\title{
Prevalence of long-term use of medicines with prolonged oral clearance in the elderly: a survey in north east England
}

\author{
A. Maguire,' and W. Baqir, ${ }^{2}$
}

Aim To determine the prevalence of long-term use by the elderly of prescribed and over-the-counter (OTC) medicines with prolonged oral clearance (POC), with regard to sugars content, dose form and therapeutic groups of medicines used.

Design and setting Two cross-sectional observational surveys in ten general medical practices in north-east England during 1996.

Methods Computerised patient records of all elderly patients (aged 60 years and over) were surveyed for prescribed medicines use. Within these practices, $50 \%$ of elderly patients registered with ten general medical practitioners were surveyed by postal questionnaire to assess over-the-counter (OTC) medicines use. Results Of 20,731 elderly patients registered, prevalence of use of prescribed prolonged oral clearance (POC) medicines was $9.8 \%$ (95\% CI: 8.2\%,11.3\%) and use in females aged 75years and older was significantly more likely $(P<0.0001)$. Of 2,796 prescribing instances (PIs) for 143 POC medicines used long-term, 53\% were gastrointestinal and $72 \%$ were sugars-free; however, $82 \%$ of 542 PIs for generic liquids were sugars-containing compared with $8 \%$ of 685 PIs for proprietary liquid oral medicines. Of 1,532 elderly respondents to a postal questionnaire, 17 were using 13 different OTC medicines with POC regularly and long-term (mean prevalence; $1.1 \%$ ). Of the 17 instances of regular long-term use of OTC medicines, $59 \%$ were sugars-free.

Conclusions Prescribed medicines represent the bulk of regular, long-term medicines use in the elderly. Generic prescribing is more likely to result in sugars-containing medicines being dispensed. Generic medicines manufacturers must be encouraged to provide sugars-free alternatives to POC medicines used long-term, and health professionals should be vigilant when prescribing and dispensing these medicines to the increasingly dentate elderly.

Tn 1974, there were 10.9 million adults aged 60 years and older in the UK; this number had increased to 12 million by $1994,{ }^{1}$ when the elderly represented $21 \%$ of the 58.4 million population. This growth has been primarily caused by the numbers of 'old elderly' increasing from 2.7 million to 4 million over this period with 'young elderly' remaining fairly constant at around 8 million. ${ }^{1}$ Advances in healthcare together with improvements in living conditions and lifestyles have been chiefly responsible for these changes. However, with ageing comes a higher dependency on

\footnotetext{
$1^{*}$ Clinical Lecturer, ${ }^{2}$ Honorary Research Associate, Department of Child Dental Health, University of Newcastle upon Tyne

${ }^{*}$ Correspondence to: Dr A. Maguire, Department of Child Dental Health, School of Dentistry, Framlington Place, Newcastle upon Tyne, NE2 4BW

REFEREED PAPER

Received 22.11.99; accepted 6.03.00

(c) British Dental Journal 2000; 189: 267-272
}

medication for chronic medical problems. The elderly consume more prescribed medication per head than any other age group: three times more than younger adults and four times more than children. In 1994, the elderly who were exempt from prescription charges were dispensed a mean of 20.7 prescription items per head. For children, a mean of 4.7 items per head, and for non-elderly adults 6.1 items per head were dispensed during the same year. ${ }^{2}$ As the above demographic changes have occurred, improvements in dental healthcare and changes in attitudes to health and disease have led to an elderly population which is increasingly dentate. ${ }^{3}$

Sugars in the diet remain a primary factor in dental caries aetiology. ${ }^{4}$ The form in which sugars are presented to the oral cavity is also important. If sugars linger in the mouth and the sugarscontaining product is used regularly and long-term, then the risk to dental health is greater. ${ }^{5}$ When medicines in liquid, syrup, or chewable tablet form contain sugar and are used long-term for the treatment of chronic disease, ${ }^{6-9}$ they pose a greater threat to dental health than those dose forms which are swallowed immediately (e.g. tablets and capsules). This increased risk is caused by the longer time taken for these dose forms to clear from the mouth compared with tablets and capsules. Prolonged oral clearance (POC) medicines are usually formulated as these dose forms for a particular reason. For example, an antacid is most efficacious in liquid form to maximise the surface area of the drug in contact with stomach acid. In addition, a liquid dose form may be used to optimise compliance of paediatric and geriatric patients with a particular medication regime where they may have difficulty in swallowing solid doses.

The sugars-free option for paediatric medicines has been well publicised in the UK, ${ }^{10-12}$ and some community-based sugars-free medicines campaigns have had some success in limiting the use of sugars-containing medicines in children. ${ }^{13,14}$ However, the picture for geriatric medicines is less clear; there is no information on the extent of use of these medicines with prolonged oral clearance. In addition, it is not clear whether the impact of generic prescribing, which has been shown to increase the chance of a sugars-containing medicine being dispensed for children, ${ }^{15}$ has a similar effect in the elderly. With these potential risk factors in mind, a study was undertaken to determine the prevalence of regular and long-term use of prescribed and over-the-counter (OTC) medicines with prolonged oral clearance, both sugars-containing and sugars-free, in the elderly. This was achieved through two surveys of elderly patients in general medical practices in north-east England.

\section{Materials and Method}

Prescribed medicines survey

A survey of prescribed medicines used by the elderly was conducted in the five district health authorities of Newcastle, Gateshead, North Tyneside, South Tyneside and Northumberland. Following approval by the relevant local research ethics committees, a list of general medical practices with comprehensive computing facilities was requested 
from each of the five health authorities. A cluster sampling technique was used for data collection, with each cluster comprising all elderly patients aged 60 years and over registered in a general medical practice. Criteria for including a practice in the survey were:

- Computerised patient medication records (PMRs)

- A large list size (5000 patients or greater)

- A good socioeconomic mix of patients of all ages.

Of 199 practices in the 5 districts, 125 operated comprehensive computer systems and 84 met all the inclusion criteria. Ten practices, two from each district, were chosen randomly. The senior partner at each of the 10 selected practices was contacted by letter, inviting the practice to participate in the study. Following practice agreement, arrangements were made to retrieve data for all patients aged 60 years and over registered with the practice and taking medicines with prolonged oral clearance regularly (daily or alternate day) and long-term (for 3 months or longer). Data collection was carried out in three phases between March 1996 and March 1997: in Phase 1 (March-June 1996), the computer records of all elderly patients aged 60 years and older were examined and those patients taking medicines with prolonged oral clearance were highlighted; Phase 2 (July-November 1996) involved the examination of the medication schedule for highlighted patients to collect further information on those patients taking these medicines regularly and long-term; and in Phase 3, medication and prescribing details for identified patients were entered into a relational database for subsequent analysis. The data retrieved included practice, gender and age of each patient identified and their medical problems, as well as the dose, frequency of administration and date of commencement of treatment for each POC medicine currently prescribed. The records of 100 patients $(20$ from each of 5 practices) were chosen randomly to quantify errors in collection, coding and entry of data. In addition, using a list of all medical and surgical products available at the time, supplied by John Richardson Computers (John Richardson Computers plc, NDC, Preston, UK), a database of all oral medicines with prolonged oral clearance was created, which included:

- Classification of the medicine according to the British National Formulary 16

- A medicine code to identify each individual preparation

- Dose form (eg liquid, solid or powder)

- Manufacturer, and

- If the medicine was available as a generic formulation(s).

The medicines with prolonged oral clearance were coded according to dose form (i.e. liquid oral medicines, solids with prolonged oral clearance, oral gels and powders, and powders in sachets). Each prescribed medicine a patient was currently taking was recorded as a prescribing instance $(\mathrm{PI})$.

A number of sources of information were used to obtain current information for the sweetening agent contained in each preparation. These were: a) The British National Formulary, ${ }^{16}$ b) The Association of the British Pharmaceutical Industry (ABPI) Data Sheet Compendium (1995-96), ${ }^{17}$ and c) Direct approach to medical information departments of individual pharmaceutical manufacturers. Guidelines in the British National Formulary, which advise that oral liquid preparations that do not contain fructose, glucose or sucrose can be labelled as 'sugars-free, ${ }^{16}$ were applied in this study.

Demographic data for England, the Northern Region and the five districts (Newcastle, North Tyneside, Gateshead, South Tyneside and Northumberland) were obtained from the Office of National Statistics. ${ }^{18}$

The prevalence of elderly persons aged 60 years and older taking prolonged oral clearance medicines regularly and long-term was calculated by dividing the number of elderly identified in all ten practices in the five districts by the total number of elderly in this age group registered in the ten practices.

Statistical analysis was undertaken using a chi-squared test, to identify statistically significant $(P<0.05)$ effects of age group and gender (adjusted for age) for patients taking medicines with POC regularly and long-term.

\section{Over the counter medicines survey}

Following local research ethics committee approval, a postal questionnaire was designed with advice from the Centre for Health Services Research at the University of Newcastle. Close attention was paid to its construction and content to optimise reliability and validity. The questionnaire was then piloted with 196 patients aged 60 years and over registered with one general medical practitioner from one practice used in the prescribed medicines survey. Accompanied by a letter signed by their doctor, the questionnaire gathered information on the patient's dental status, medical conditions and medication schedule for all medicines (both prescribed and OTC) currently taken. In the pilot study, patients were asked to complete the questionnaire as well as an evaluation form which collected comments about layout, ease of reading and any difficulties in understanding the questions contained in the questionnaire.

Following statistical advice, ten general medical practitioners from the 47 included in the prescribed medicines survey (the general medical practitioner used for the pilot study was excluded from the study), were randomly sampled. Fifty per cent of each practitioner's elderly patients were then randomly sampled for inclusion in a postal questionnaire survey of OTC medicines use. Just prior to postal distribution, an enquiry was made to each participating practice to ensure that all sampled patients were still registered. Each questionnaire was accompanied by a letter signed by the patient's doctor, encouraging participation but reassuring patients that their medical care would not be affected if they declined. Freepost return envelopes were used, each of which carried an identification number relating to the patient. This number was transferred to the completed questionnaire upon receipt to ensure that the two reminders were sent only to non-respondents. In addition, all mailing included a telephone number to allow patients to contact a researcher (WB) with any query relating to the questionnaire. Data from completed questionnaires were entered into the relational database described above, along with information on the sugars content of OTC medicines, retrieved from the sources mentioned above as well as the OTC Directory - Treatments for Common Ailments. ${ }^{19}$ From these data, the prevalence of regular and long-term use of OTC medicines with prolonged oral clearance by the elderly in the sample was determined.

\section{Results}

\section{Prescribed medicines survey}

Of the 10 practices approached at the start of the survey, 8 agreed to participate. Two stated that they were too involved in other research to be able to co-operate and therefore two further practices in the same districts were sampled randomly from the remaining practices meeting the inclusion criteria. Of the 92,570 patients of all ages registered in the 10 general medical practices surveyed, 20,371 $(22 \%)$ were aged 60 years and over. Of these elderly, 3,777 (18.5\%) were currently taking prescribed medicines with POC and 2,002 had been prescribed these medicines for 3 months or longer and had been taking them on a regular basis (once or alternate daily). This represented an overall prevalence of regular and long-term use of POC medicines in this elderly population of $9.8 \%$ (95\% confidence intervals: $8.2 \%, 11.3 \%$ ). In $60-74$-year-olds the mean prevalence was $7.8 \%$ (95\% confidence intervals: $6.2 \%, 9.4 \%)$ and in those 75 years and older it was $13.5 \%$ (95\% confidence intervals: $11.5 \%, 15.5 \%)$. Statistical analysis showed that females aged 
75 years and older were more likely to be taking medicines with prolonged oral clearance regularly and long-term than other age and gender groups $(P<0.0001)$.

Of the 2,002 patients taking POC medicines long-term, cardiovascular problems were recorded in $38 \%$, and musculoskeletal and joint disorders in $24 \%$. Overall, at the time of the survey, these elderly accounted for a total of 11,751 prescribing instances (PIs), of which 2,796 (24\%) PIs were for oral medicines with POC used long-term (Table 1). These 2,796 PIs were for 143 different medicines (Table 2), of which 59\% were liquid oral medicines accounting for $44 \%$ of the total number of long-term prescribing instances, $29 \%$ being for solids with prolonged oral clearance representing $45 \%$ of prescribing instances. Table 2 also shows the distribution of preparations and prescribing instances according to the specificity of prescribing (i.e. by proprietary or generic name); $29 \%$ of preparations but $52 \%$ of prescribing instances being for generic medicines. A relatively new dose form, the sachet, accounted for only $9 \%$ of the preparations and $10 \%$ of the total number of long-term prescribing instances, however almost all (>99\%) of these PIs were for proprietary medicines.

The main therapeutic areas of use for medicines with prolonged oral clearance in the elderly were gastrointestinal medicines $(36 \%$ of preparations, $53 \%$ of prescribing instances), central nervous system and cardiovascular medicines (Figure 1 ).

The sugars content of these medicines prescribed to the elderly was considered in relation to dose form and the impact of generic prescribing. Of the 143 preparations with prolonged oral clearance used long-term (Table 2), 101 (71\%) were proprietary preparations and $42(29 \%)$ were generic preparations. However, in total, the generic preparations were available as 144 different formulations from 27 different generic manufacturers. The quality of information

Table I Distribution of I I,75 I prescribing instances (PIs) for all medicines being used by $\mathbf{2 , 0 0 2}$ elderly people, identified as taking one or more medicines with prolonged oral clearance (POC) regularly and long-term (for 3 months or longer) at the time of the prescribed medicines prevalence survey. Medicines are classified according to dose type, and duration of use

\begin{tabular}{|c|c|c|c|}
\hline $\begin{array}{l}\text { Medication } \\
\text { category }\end{array}$ & $\begin{array}{l}\text { No. of Pls } \\
\text { prescribed }\end{array}$ & $\begin{array}{c}\text { Pls as } \% \text { of } \\
\text { total } \\
\text { prescribed }\end{array}$ & $\begin{array}{l}\text { No. of Pls } \\
\text { per patient }\end{array}$ \\
\hline $\begin{array}{l}\text { Oral medicines without POC } \\
\text { (tablets or capsules) }\end{array}$ & 6,295 & 53 & 3.1 \\
\hline $\begin{array}{l}\text { Non-oral medicines } \\
\text { (creams, inhalers, injections) }\end{array}$ & $|, 83|$ & 16 & 0.9 \\
\hline $\begin{array}{l}\text { Medicines with POC } \\
\text { used 'when required' }\end{array}$ & 829 & 7 & 0.4 \\
\hline Medicines with POC used long-term & 2,796 & 24 & 1.4 \\
\hline Total & $|I, 75|$ & 100 & 5.8 \\
\hline
\end{tabular}

Table 2 Number of preparations and prescribing instances (PIs) for I43 preparations with prolonged oral clearance, identified as being used regularly and long-term by 2,002 elderly patients in 10 general medical practices; classified according to dose form and whether they were generic or proprietary medicines

\begin{tabular}{|c|c|c|c|c|c|c|c|c|c|c|c|c|}
\hline \multirow[t]{3}{*}{ Dose form } & \multicolumn{4}{|c|}{ Generic } & \multicolumn{4}{|c|}{ Proprietary } & \multicolumn{4}{|c|}{ Total } \\
\hline & \multicolumn{2}{|c|}{ Preparations } & \multicolumn{2}{|c|}{ Pls } & \multicolumn{2}{|c|}{ Preparations } & \multicolumn{2}{|c|}{ Pls } & \multicolumn{2}{|c|}{ Preparations } & \multicolumn{2}{|c|}{ Pls } \\
\hline & No. & $\%$ & No. & $\%$ & No & $\%$ & No. & $\%$ & No. & $\%$ & No. & $\%$ \\
\hline Liquid oral medicines & 31 & 74 & 542 & 37 & 54 & 53 & 685 & 51 & 85 & 59 & 1,227 & 44 \\
\hline $\begin{array}{l}\text { Solids with prolonged } \\
\text { oral clearance }\end{array}$ & 10 & 24 & 909 & 63 & 31 & 31 & 342 & 26 & 41 & 29 & $|, 25|$ & 45 \\
\hline Powders and oral gels & 0 & 0 & 0 & 0 & 4 & 4 & 19 & I & 4 & 3 & 19 & I \\
\hline Sachets & $\mathrm{I}$ & 2 & I & $<1$ & 12 & 12 & 298 & 22 & 13 & 9 & 299 & 10 \\
\hline Total & 42 & 100 & 1,452 & 100 & 101 & 100 & $\mathrm{I}, 344$ & 100 & 143 & 100 & 2,796 & 100 \\
\hline
\end{tabular}

Fig. I Distribution of 143 preparations and 2,796 prescribing instances (PIs) for medicines with prolonged oral clearance used regularly and long-term by 2,002 elderly patients in 10 general medical practices; classified according to the British National Formulary (BNF) ${ }^{16}$

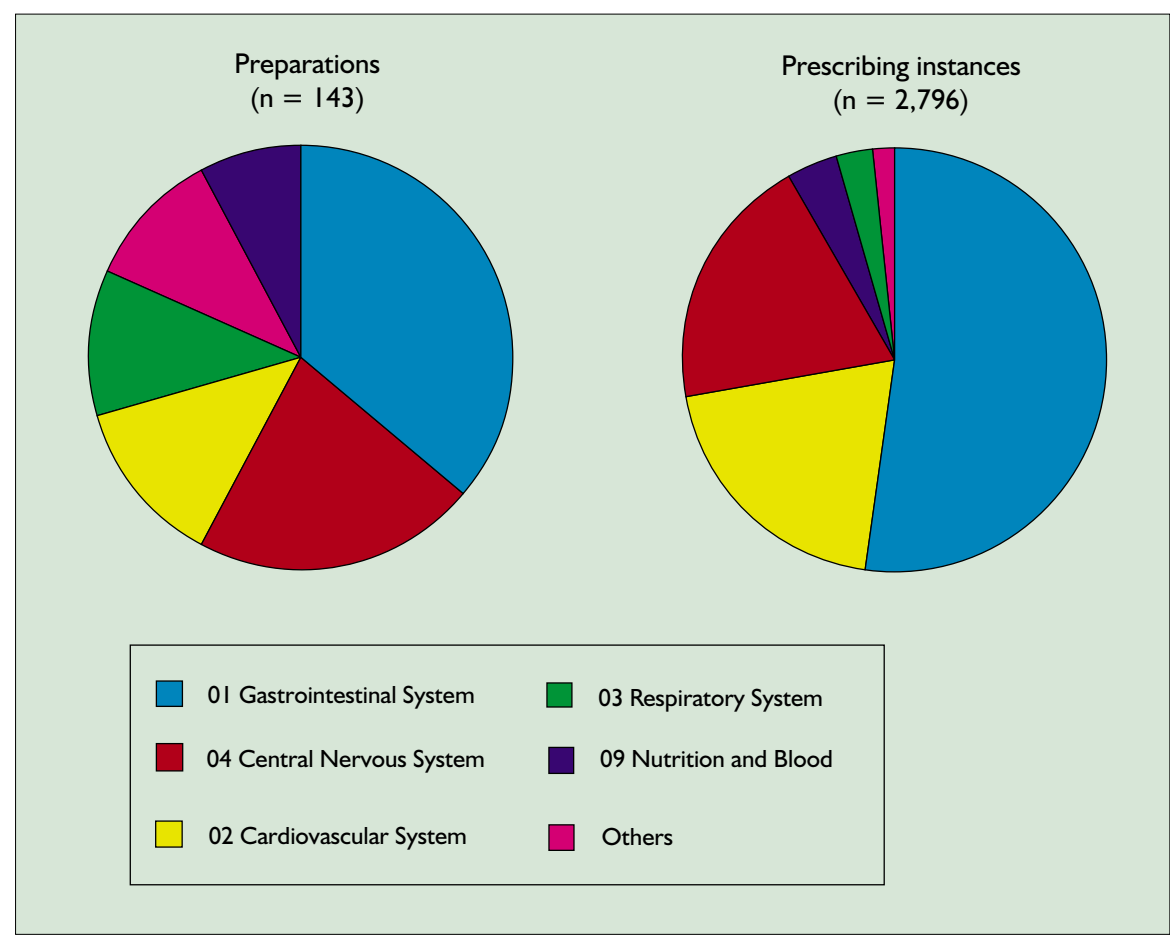


Fig. 2 Distribution of the I,452 prescribing instances (PIs) for generic (gen) formulations and the I,344 prescribing instances (PIs) for proprietary (prop) formulations with prolonged oral clearance used regularly and long-term by 2,002 elderly patients in 10 general medical practices; classified according to dose form and sugars content. (LOMs = liquid oral medicines)

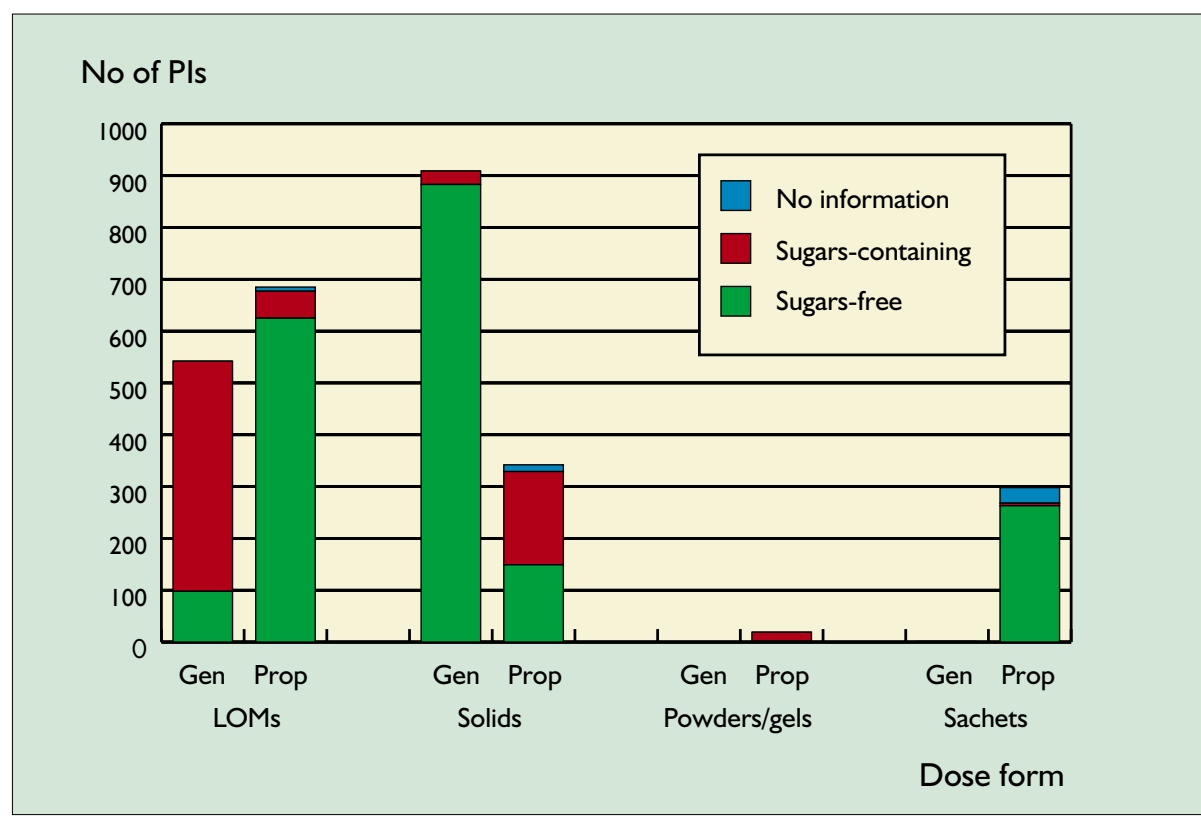

obtained from manufacturers regarding the sugars content of their medicines was variable. Generic manufacturers were prepared to state whether their formulation was sugars-free or sugars-containing but more detailed information on the amount and nature of the actual sweetening agent used was provided for only $46 \%$ of the 144 generic formulations. Proprietary manufacturers were more forthcoming and detailed information on the sweetening agents was provided for $96 \%$ of the 101 products used.

The distributions of sugars-containing and sugars-free prescribing instances by dose form are shown for generic and proprietary preparations in Figure 2. Overall, of the 2,976 prescribing instances for long-term use of POC medicines, 1,452 (52\%) were for generic preparations, of which $68 \%$ were sugars-free, and 1,344 (48\%) were for proprietary preparations, of which $77 \%$ were sugars-free. However, when dose forms were considered separately, the contrast was marked; $91 \%$ of the 685 proprietary PIs for liquid oral medicines were sugars-free, however, only $18 \%$ of the 542 generic PIs for liquid oral medicines were sugars-free. The majority of these sugars-containing generic medicines were laxatives. In contrast, for solids with prolonged oral clearance, which included lozenges, buccal and chewable tablets, of the 342 prescribing instances for proprietary preparations, only $43 \%$ were sugars-free, whereas $97 \%$ of the 909 prescribing instances for generic solids with POC were sugars-free (Figure 2). The sugars-containing proprietary solids were mainly antacids formulated as chewable tablets and buccal tablets used in the prevention of angina.

The five most prescribed medicines with POC used regularly and long-term represented $66 \%$ of the total number of prescribing instances for long-term use (Table 3). Aspirin, as a $75 \mathrm{mg}$ dispersible tablet used the prevention of cardiac disease, accounted for $460(16 \%)$ prescribing instances.

\section{OTC medicines survey}

Of the 2,322 questionnaires posted, 1029 (44.3\%) were returned after the first mailing, another $308(13 \%)$ and $324(14 \%)$ after the first and second reminder respectively. Of the 1,661 (72\%) replies, 1,532 were usable, representing an overall response rate of $66 \%$. The telephone contact number for answering queries was used by 141 patients. Of the 1,532 respondents included in the OTC medicines survey, $57.2 \%$ were female, $67.8 \%$ were patients aged 60 to 74 years. This was very similar to the age and gender profiles of the elderly patients of the 10 general medical practices where $57.1 \%$ were female and $66.1 \%$ aged 60-74 years, suggesting that
Table 3 The five most commonly prescribed POC medicines used regularly and long-term by 2002 elderly patients in 10 general medical practices

\begin{tabular}{|c|c|c|c|c|}
\hline Preparation & $\begin{array}{l}\text { BNF } \\
\text { Chapter* }\end{array}$ & \multicolumn{2}{|c|}{$\begin{array}{l}\text { Prescribing } \\
\text { instances }\end{array}$} & $\begin{array}{l}\% \\
\text { Prescribed } \\
\text { generically }\end{array}$ \\
\hline Aspirin $75 \mathrm{mg}$ dispersible tablets & CVS & 460 & 16 & 100 \\
\hline $\begin{array}{l}\text { Sodium alginate } 250 \mathrm{mg} / \text { sodium } \\
\text { bicarbonate } 133.5 \mathrm{mg} / \text { calcium } \\
\text { carbonate } 80 \mathrm{mg} / 5 \mathrm{ml} \text { liquid }\end{array}$ & GIT & 423 & 15 & 0 \\
\hline $\begin{array}{l}\text { Co-codamol } 500 \text { mg/8 mg } \\
\text { effervescent tablets }\end{array}$ & CNS & 363 & 13 & 100 \\
\hline Lactulose liquid & GIT & 350 & 13 & 100 \\
\hline Ispaghula husk $3.5 \mathrm{~g}$ sachets & GIT & 255 & 9 & 33 \\
\hline Others & & 945 & 34 & - \\
\hline Total & - & 2,796 & 100 & - \\
\hline
\end{tabular}

*CVS = Cardiovascular, GIT = Gastrointestinal, $\quad$ CNS $=$ Central Nervous System

respondents were representative of the 20,371 elderly registered in the 10 practices. Of the 1,308 patients ( $85 \%$ of respondents) who noted a medical problem, $36 \%$ reported cardiovascular disease, $24 \%$ musculoskeletal and joint disorders.

Overall, $46 \%$ of the respondents were dentate and $32 \%$ had more than 12 natural teeth (60-74 years; $54 \%$ dentate, 75 years and older; $29 \%$ dentate). Seventy-nine patients were using OTC preparations with POC, and they accounted for 88 instances of the current use of 44 OTC preparations. Of these patients, 17 had been using OTC medicines with POC for 3 months or longer at the time of the survey (Table 4). This represented a mean prevalence of $1.1 \%$. Interestingly, only three of these 17 patients reported a medical problem, none of which was related to the OTC medicine which they were taking long-term. Of the 17 instances of regular and long-term use, $53 \%$ were for liquid oral medicines and overall $59 \%$ were for sugarsfree products (Table 4). 'Nutrition and blood' preparations, (specifically cod liver oils and tonics), represented $29 \%$ of all instances of long-term use, $80 \%$ of which were sugars-free, whereas of gastrointestinal preparations (antacids and laxatives) which represented 4 $(23 \%)$ instances of use, $25 \%$ were sugars-free. All central nervous system medicines and cardiovascular system products were sugarsfree and were all effervescent or dispersible tablets; however, none of the respiratory products used long-term were sugars-free. Sucrose was the most common sweetening agent — found in five of the six 


\section{RESEARCH therapeutics}

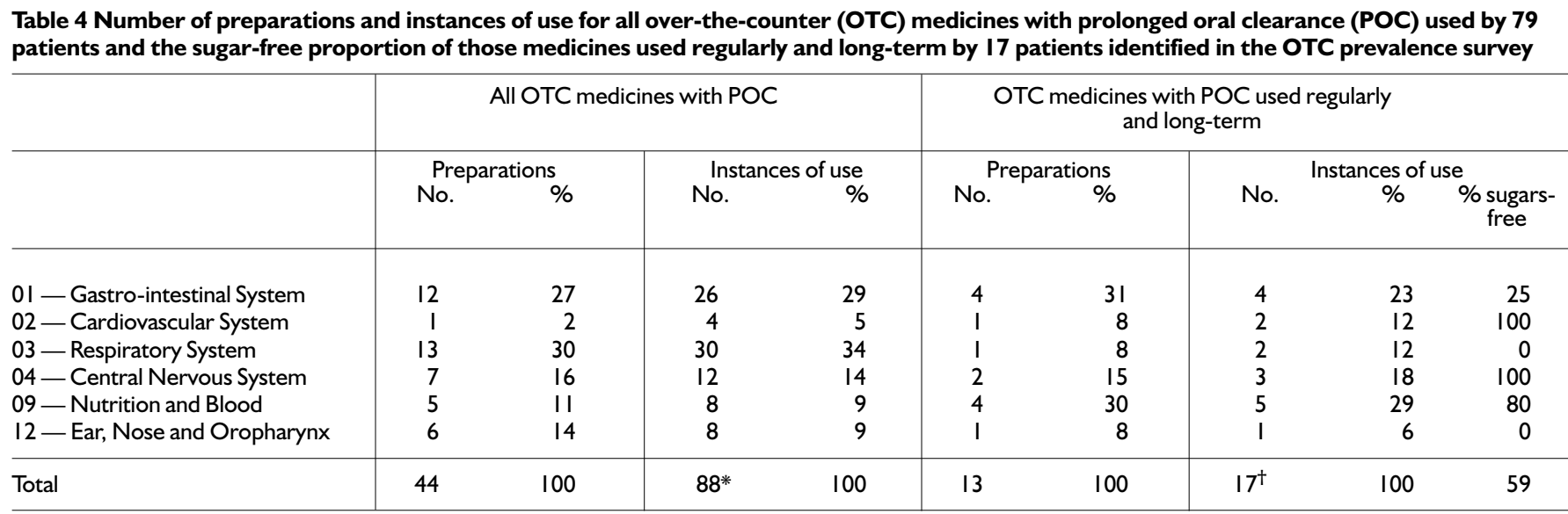

*Taken by 79 patients

†Taken by 17 patients

sugars-containing OTC medicines - with saccharin being the most common sweetening agent for sugars-free medicines.

\section{Discussion}

The use of two prevalence surveys, one of which was conducted on a sub-sample of the first, made it possible to look at overall medicines use in the elderly from all sources. This was important, since a survey concentrating purely on patient records held in general medical practice was unlikely to gain information on the use of medicines purchased over the counter from community pharmacies and other retail outlets. The information retrieved on medicines use was that reported by the elderly themselves. Overall, the response rate to this questionnaire was $66 \%$, which was acceptable and largely representative of the elderly in the ten practices. The inclusion of a letter from the patient's general medical practitioner in the initial mailing as well as duplicate questionnaires in the two reminders helped to maximise the response rate.

It could be argued that collection of medication data directly from patients, providing it is reliable, can provide a better estimate of the actual use of medicines than information recorded on patient records in general medical practices. Patient medication records provide information on medicines prescribed, but since compliance with medication, especially in the elderly, is poor, this is of limited value in studies of medicines use. Up to $50 \%$ of the elderly may not comply with their medication and as numbers of tablets taken and dosing frequency increase, compliance with medication reduces. ${ }^{21}$ In the OTC medicines survey, great efforts were made to simplify completion of the questionnaire to maximise its reliability. Since the OTC Survey was carried out on a subsample of the elderly surveyed in the prescribed medicines survey, it was possible to cross-check reported prescribed medicines use by respondents with actual prescribing of medicines by the general medical practitioner. This showed a high degree of reliability in reporting by OTC medicines survey respondents.

The prevalence of the use of medicines with prolonged oral clearance long-term in the elderly in 10 general medical practices in north-east England was determined to be around 9.8\% for prescribed medicine use and $1.1 \%$ for OTC medicine use. These results indicated that in the Northern Region as a whole, with an elderly population of 0.62 million, ${ }^{15}$ around 60,760 persons aged 60 years and over may have been taking prescribed medicines with prolonged oral clearance long-term at the time of the survey, with up to 6,820 elderly taking OTC medicines with POC long-term. However, the results suggest a slight overlap of these groups as 3 $(18 \%)$ of the patients identified in the OTC prevalence survey were also taking a prescribed medicine with POC long-term and were identified in the prescribed medicines survey.

With regard to the sugars content of these medicines, the poor response from generic manufacturers was regrettable, as health professionals will increasingly need to consult them for essential information as generic prescribing and dispensing increases in line with government recommendations.

When all dose forms of medicines (oral, non-oral, POC and non POC) were included, a mean of 5.8 medicines per head were being used at the time of the survey for those 2,002 elderly individuals taking prescribed POC medicines long-term. It was not possible to compare this level of use with other studies since the group included in the survey was very specific and medicines use analysed by dose form has not been studied previously in the elderly. However, in the elderly population as a whole in the UK, medicine use has been recorded as 2.8 medicines per head ${ }^{20}$ increasing significantly with age and in the institutionalised elderly. It may be that those persons requiring prolonged oral clearance medicines may be more frail than those individuals using standard solid oral dose forms such as tablets and capsules since dose forms with prolonged oral clearance are more 'user friendly' for those individuals with swallowing difficulties.

Overall, $72 \%$ of 2,796 PIs for POC medicines used long-term were sugars-free: however, only $60 \%$ of PIs for liquid oral medicines and $18 \%$ of generically prescribed oral liquids used were sugars-free. In addition, a substantial proportion (53\%) of PIs for proprietary solids with POC were sugars-containing, which is of some concern as these particular dose forms are relatively new. Health professionals involved in the prescribing and dispensing to the elderly and responsible for maintaining optimal oral health in their dentate elderly patients must be made aware of these particular medicines and the risk they may present, especially in those patients who may have salivary flow compromised by concurrent use of other medications. ${ }^{22}$

The proportion of the 1,532 respondents to the postal questionnaire who were dentate was similar to the proportions of dentate elderly found in the 1988 UK national adult dental health survey: which recorded $51 \%$ of $55-64$-year-olds and $39 \%$ of $65-74$-yearolds in the North as dentate. ${ }^{3}$ Extrapolation of the results of the current study to the Northern Region as a whole indicate that as many as 8,500 elderly individuals with some natural teeth may be at risk from medicines containing sugars prescribed long-term. Although the prevalence of use of OTC medicines was lower, the proportion which were sugars-containing was higher (41\%), with up to 1,286 dentate elderly in the Northern Region at risk from OTC medicines containing sugars.

General medical problems recorded in the prescribed and OTC 
medicine surveys showed a similar pattern of disease to that commonly described in the elderly. Cardiovascular problems were recorded in $38 \%$ of the 2,002 patients taking POC medicines longterm and $36 \%$ of the 1,308 patients who reported a medical problem in the OTC survey. Prescribing data for all medicines dispensed to elderly patients (those exempt from prescription charges) in England in 1994 showed that the largest group of medicines prescribed were cardiovascular medicines accounting for $27.6 \%$ of all 184 million prescription items dispensed, with central nervous system medicines accounting for $19.5 \% .^{23}$ Therapeutic groups of POC medicines used long-term did not completely reflect the medical problems for which the elderly are commonly prescribed medicines in primary care. Gastro-intestinal medicines such as antacids and laxatives were used most commonly in these surveys, reflecting the nature of dose forms with prolonged oral clearance, formulated in this particular way for optimal efficacy. However, central nervous system medicines with POC were also very commonly used and this pattern of use was mainly caused by the increasing use of minor analgesics in effervescent tablet form.

The vast majority of over-the-counter medicines are indicated for short-term use; pharmacists are trained to discourage patients from using them regularly and long-term. The few OTC medicines indicated for long-term use include vitamin supplements and mineral replacement products such as cod liver oil, however, 8 of the 13 OTC medicines used long-term were not indicated for long-term use. These were antacids, laxatives, cough medicines and analgesics which should be used on a 'when required' basis but were being used for periods of between 3 months and 2 years. This was of some concern since the use of OTC preparations may mask more serious conditions presenting as dyspepsia, constipation, cough and general pain. Currently, pharmacists can only monitor regular use of these OTC medicines when bought from the same pharmacy. Improving patient knowledge about the risks associated with abuse of OTC medicines is required to ensure appropriate use. The introduction of patient records of OTC medicines sales, perhaps linked to existing pharmacy systems could highlight those at risk.

The most commonly prescribed POC medicine was aspirin $75 \mathrm{mg}$ dispersible tablet, its use being associated with a reduction in risk of subsequent myocardial infarction in patients with pre-existing cardiovascular disease and in primary prevention. Despite strong evidence for its benefits, it has been shown that many at risk patients do not receive aspirin on prescription, ${ }^{24}$ however, many patients may be buying it OTC $^{25}$ and not all will be monitored by their general medical practitioner, since anecdotal evidence suggests that some patients may buy this medicine as a result of press publicity about its health benefits.

Although OTC medicines represented a small proportion of overall use of medicines with prolonged oral clearance, there is strong evidence to suggest that OTC medicine use is increasing overall, with government encouraging patients with minor ailments to visit a pharmacist before seeking advice of a general medical practitioner. ${ }^{26}$ As a result, sales of OTC medicines in 1996 were equivalent to one-third of the NHS drugs bill. ${ }^{27}$ In addition, since more OTC medicines are becoming available as generics, they may be more likely to contain sugars and the threat to dental health may increase.

\section{Conclusion}

Prescribed medicines with prolonged oral clearance represent the bulk of regular, long-term use of medicines with prolonged oral clearance in the elderly. Pharmaceutical manufacturers, particularly generic manufacturers must be made aware of those medicines with prolonged oral clearance likely to be used long-term and encouraged to provide sugars-free alternatives where necessary. The role of the health professional is also crucial; they should be vigilant when prescribing, dispensing and monitoring medicines with prolonged oral clearance, particularly generic medicines, as they may pose a threat to the dental health of their increasingly dentate elderly patients.

The authors wish to thank the doctors and staff in all ten general medical practices surveyed, for their co-operation, and the patients, who by kindly completing and returning their questionnaires, made this study possible.

1 Office of Population Censuses and Surveys. Mid-1994 population estimates for England and Wales. OPCS Monitor, PP1 95/1. London: HMSO, 1995.

2 Government Statistical Service. Statistical Bulletin 1998/24. Statistics of Prescriptions dispensed in the FHSAs: England 1987 to 1997. London: HMSO, 1998.

3 Todd J E, Lader D. Adult dental health 1988, United Kingdom. Office of Population Censuses and Surveys. pp1-422. London: HMSO,1992.

4 Rugg-Gunn A J. Dental caries- the role of dietary sugars. In: Nutrition and dental health. Oxford: Oxford University Press, 1993

5 Dawes C. Clearance of substances from the oral cavity- implications for oral health. In: Edgar W M, O'Mullane D M (ed) Saliva and oral health. 2nd edition. London: British Dental Association, 1996.

6 Roberts I F, Roberts G J. Relation between medicines sweetened with sucrose and dental disease. Br Med J 1979; 2: 14-16.

7 Roberts I F, Roberts G J. Dental disease in chronically sick children. J Dent Child 1981; 48: 346-351.

8 Feigal R J, Gleeson M C, Beckman T M, Greenwood M E. Dental caries related to liquid medication intake in young cardiac patients. J Dent Child 1984; 51: 360-362.

9 Maguire A, Rugg-Gunn A J, Butler T J. Dental health of children taking antimicrobial and non-antimicrobial liquid oral medication long-term. Caries Res 1996; 30: 16-21.

10 Hobson P. Sugar based medicines and dental disease. Community Dent Health 1985; 2: 57-62.

11 Hobson P, Fuller S. Sugar-based medicines and dental disease - a progress report. Community Dent Health 1987; 4: 167-176.

12 Mackie I, Hobson P. Factors affecting the availability of sugar-free medicines for children — a survey in the UK. Int J Paediat Dent 1993; 3 : 163-167

13 Bentley E, Mackie I, Fuller S. The rationale, organisation and evaluation of a campaign to evaluate and increase the use of sugar-free paediatric medicines. Community Dent Health 1997; 14: 36-40.

14 Evans D J, Howe D, Maguire A, Rugg-Gunn A J. Development and evaluation of a sugar-free medicines campaign in North East England: analysis of findings from questionnaires. Community Dent Health 1999; 16: 131-137.

15 Maguire A, Rugg-Gunn A J. Medicines in liquid and syrup form used long-term in paediatrics: a survey in the Northern Region of England. Int $J$ Paediatr Dent 1994; 4: 93-99.

16 British Medical Association \& Royal Pharmaceutical Society. The British National Formulary, Number 29. London: British Medical Association \& Royal Pharmaceutical Society of Great Britain, 1995.

17 Association of British Pharmaceutical Industry. Compendium of Date Sheets. London: Datapharm Publications Limited, 1995.

18 Office for National Statistics. Key population and vital statistics - local and health authority areas. Regional trends. VS no. 22 PP1, No. 18. London: HMSO, 1995.

19 Proprietary Association of Great Britain. OTC Directory 1994. Treatments for common ailments. London: PAGB, 1994.

20 Consumers Association. Elderly people: their medicines and their doctors. Drug Therapeutics Bull 1990; 28: 77-79.

21 Royal Pharmaceutical Society of Great Britain. From compliance to concordance. Achieving shared goals in medicine taking. London: Pharmaceutical Press, 1997.

22 Perrson R E, Izutsu K T, Truelove E L, Perrson R. Differences in salivary flow rates in elderly subjects using xerostomatic medications. Oral Surg, Oral Med, Oral Path, Oral Radiol Endod 1991; 72: 42-46.

23 Prescription Pricing Authority. Prescription analysis. January 1994 to December 1994. Distribution by sub-therapeutic group (Elderly Exempt Prescriptions). Newcastle upon Tyne: Department of Health, 1995.

24 McCallum A K, Whincup P H, Morris R W, Thompson A, Walker M, Ebrahim S. Aspirin use in middle-aged men with cardiovascular disease: are opportunities being missed? Br J Gen Pract 1997; 47: 417-421.

25 Hoper S, Pierce M. Aspirin after myocardial infarction: the importance of over the counter use. Family Pract 1998; 15: S10-S13.

26 Baines D L, Whynes D K. Over the counter drugs and prescribing in general practice. Br J Gen Pract 1997; 47: 221-224.

27 Blenkinsop A, Bradley C. Patients, society and the increase in self medication. Br Med J 1996; 312: 629-632. 